\title{
Social Media as a Platform for Information and Support for Melanoma Patients: Analysis of Melanoma Facebook Groups and Pages
}

Nishita Maganty, MPH; Muneeb Ilyas, BS; Zachary Ginsberg; Amit Sharma, MD

Department of Dermatology, Mayo Clinic Arizona, Scottsdale, AZ, United States

\section{Corresponding Author:}

Nishita Maganty, MPH

Department of Dermatology

Mayo Clinic Arizona

13400 E. Shea Boulevard

Scottsdale, AZ, 85259

United States

Phone: 14803016169

Email: nmaganty@email.arizona.edu

\section{Abstract}

Background: Social media is increasingly used as a source of health information and is useful for information exchange and patient support.

Objective: The aim of this study is to describe the Facebook groups and pages that are available for melanoma patients.

Methods: A systematic search of Facebook groups and pages was performed using the word "melanoma." The first 50 pages found in the search, sorted by most relevant, were analyzed for several characteristics, namely page name, category, verification status, number of likes, number of followers, visitor posts per week, page posts per week, ability to donate, date of inception, and for-profit or nonprofit. The first 50 groups found in the search, sorted by most relevant, were analyzed for name, category, number of members, and privacy setting.

Results: There were 669 pages and 568 groups related to melanoma found on Facebook. The first 50 pages had a combined total of 266,709 likes and 257,183 followers and, of these, 30\% (15/50) were verified by Facebook. Within the analyzed Facebook pages, the average number of visitor posts per week was 0.48 , the average number of posts by the page per week was 5.6, and the most common page categories were community and nonprofit. Of the 50 groups analyzed, 18 were public and 32 were private (closed). The total number of combined group members in all 50 groups was found to be 23,047 and $52 \%$ (26/50) of the groups were categorized as support.

Conclusions: Melanoma pages and groups on Facebook reach a large portion of the population. To provide resources for the population of patients diagnosed with malignant melanoma and ensure that proper information is distributed, physicians and health care organizations may consider using Facebook as a platform to support and educate patients with melanoma.

(JMIR Dermatol 2018;1(1):e2) doi: 10.2196/derma.8482

\section{KEYWORDS}

Facebook; melanoma; online health information; patient education; support; health promotion

\section{Introduction}

According to the Centers for Disease Control and Prevention, approximately $61 \%$ of US adults have searched for medical information online [1] and due to cost, convenience, and accessibility factors [2], patients search the internet for information regarding medical conditions more often than they communicate with their doctors [3]. In addition, some patients believe that the information on the internet is better than that provided by physicians [4].

In recent years, social media websites have emerged as an easily accessible source of health information $[5,6]$ and social media is used by $39 \%$ of US adults to obtain health-related information [6]. Social media allows users to generate and share content with internet users across the world. Social networking sites have become a source of information on awareness, treatment, 
and updates regarding medical illnesses [7]. Furthermore, social networking websites allow for the creation of online support communities and create platforms to engage patients in discussion about medical conditions [7]. Facebook is one of the most popular social networking websites with nearly 2 billion active users [8]. Facebook allows users to create, share, post, and react to information. It is reported that Facebook is the fourth most popular source of health information in the United Kingdom [6]. A unique feature of Facebook is the "group" functionality, which has been defined as a space created by users to form a community of people to promote, share, and discuss a topic [9]. Another feature of Facebook is a "page" which is designed for brands, businesses, organizations, and public figures to create a presence on Facebook [10].

Skin cancer is the most common malignancy in the US and malignant melanoma is responsible for the most skin cancer related deaths [11]. The incidence of malignant melanoma is increasing worldwide and is associated with increasing health care costs [12]. Previous studies have evaluated the utility of Facebook groups in providing health education for hypertension and diabetes patients [9]; however, to date, there is no literature on the use of Facebook groups and pages by skin cancer patients, specifically those afflicted by melanoma. By gaining a better understanding of the use of Facebook for patient education, physicians, and health care organizations may be able to better utilize Facebook as a platform to support and educate patients diagnosed with malignant melanomas.

\section{Methods}

On May 23, 2017, a systematic search of Facebook in the groups and pages categories was performed using the word "melanoma." Groups and pages found in the search but were unrelated to malignant melanoma were excluded from this study. By default, Facebook provides search results by most relevant and the first 50 pages and 50 groups sorted by this method in the search results were selected for analysis in this study. The following information for each page was collected and analyzed: page name, category, verification status, number of likes, number of followers, visitor posts per week, page posts per week, ability to donate, date of inception, and for-profit or nonprofit. For each group, the following information was collected and analyzed: group name, category, number of members, and privacy setting.

Facebook pages and groups have categories identified by the relevant administers that define the main purpose of the page or group. The verification status of a page is determined by Facebook to let users know the page is authentic for a given public figure, organization, or brand. The "like" feature allows users to receive updates about a page and, if a user "likes" a page, this is displayed to their Facebook friends on their home page. The "follow" feature allows users to only receive updates from a page. The visitor posts used in this study were the posts designated under the visitor section on the Facebook pages analyzed between April 19, 2017 and April 26, 2017. The number of page posts defined in this study was the number of posts created by the page in the week of April 19, 2017and April 26,2017 . The "ability to donate" is a feature of a page that allows users to send money to the organization that created the page. The date of inception (defined as the date of inception of the organization if the page is representing an organization, or the date of inception of a page in the absence of an organization) and the type of organization (for-profit vs nonprofit) was determined by the start date and information listed on the pages' "About" sections. For the groups found in the search and analyzed, information about the number of members, privacy setting (either public or closed), and type of group was collected.

\section{Results}

Our search returned a total of 669 Facebook pages and 568 Facebook groups related to malignant melanomas. The first 50 pages had a combined total of 266,709 likes and 257,183 followers. Other features of the pages were analyzed, and Table 1 summarizes the general characteristics of the Facebook pages in this study. Of the 50 pages used in the study, 15 were verified by Facebook, 14 pages had the ability to donate feature enabled, and when the organization type was analyzed, it was found that there were 8 for-profit and 23 nonprofit pages, while the remaining 19 did not specify. For each page, the average number of visitor posts per week was 0.48 and the average number of posts by the page per week was 5.6. The categories of the pages $(\mathrm{N}=50)$ were classified as follows: personal blogs $(n=4)$, community $(n=12)$, health and wellness $(n=3)$, nonprofit $(n=11)$, charity organizations $(n=5)$, medical research centers $(n=2)$, legal companies $(n=2)$, medical and health $(n=2)$, medical center $(n=1)$, mental health service $(n=1)$, hospital $(n=1)$, event $(n=1)$, public figure $(n=1)$, cause or awareness $(n=1)$, health care administrator $(\mathrm{n}=1)$, organization $(\mathrm{n}=1)$, and medical company $(n=1)$.

Of the 50 groups analyzed, 18 were public and 32 were private (closed) and the combined number of group members across all 50 groups was 23,047. The groups were classified according to type as follows $(\mathrm{N}=50)$ : support $(\mathrm{n}=26)$, awareness $(\mathrm{n}=6)$, fundraising $(n=6)$, personal blog $(n=4)$, advocacy $(n=1)$, and not listed $(n=7)$. 
Table 1. Number and Percentage of Characteristics of Melanoma Facebook Pages (N=50).

\begin{tabular}{|c|c|}
\hline Characteristic & $\mathrm{n}(\%)$ \\
\hline \multicolumn{2}{|l|}{ Category } \\
\hline Personal blog & $4(8 \%)$ \\
\hline Community & $12(24 \%)$ \\
\hline Health and Wellness Website & $3(6 \%)$ \\
\hline Nonprofit & $11(22 \%)$ \\
\hline Charity Organization & $5(10 \%)$ \\
\hline Medical Research Center & $2(4 \%)$ \\
\hline Legal Company & $2(4 \%)$ \\
\hline Medical \& Health & $2(4 \%)$ \\
\hline Other & $9(18 \%)$ \\
\hline \multicolumn{2}{|l|}{ Verification Status } \\
\hline Verified & $15(30 \%)$ \\
\hline Not-verified & $35(70 \%)$ \\
\hline \multicolumn{2}{|l|}{ For-profit or nonprofit } \\
\hline For-profit & $8(16 \%)$ \\
\hline Nonprofit & $23(46 \%)$ \\
\hline Unspecified & $19(38 \%)$ \\
\hline \multicolumn{2}{|l|}{ Ability to Donate } \\
\hline Yes & $14(28 \%)$ \\
\hline No & $36(72 \%)$ \\
\hline
\end{tabular}

\section{Discussion}

With an increasing proportion of the population relying on social media for health information, it is necessary to understand how social networking websites are used for health information and communication. In this study, we found that there are over 600 pages and 500 groups on Facebook related to melanoma. There were a variety of different categories of Facebook pages, with community and nonprofit organizations being the most common, and these pages have an average of 5.6 posts per week. Since every like on a page suggests a visitor to that page, and since a user's Facebook friends will then see that the page was liked in their own feed, the 266,709 likes observed from the first 50 pages suggests that many people viewed these melanoma pages and that health care providers and organizations can potentially utilize Facebook pages to provide educational materials for a wider audience. The Center for Disease Control and Prevention estimates that comprehensive prevention programs could reduce the number of melanoma cases by nearly 230,000 and cut costs for melanoma treatment by US $\$ 2.7$ billion over a 10 -year period [13]. Facebook pages can also serve as a tool for patient empowerment and allow for communication with physicians and other patients. Given the high volume of posts, it is imperative that the information provided is accurate and aligns with the advice of medical professionals. One method to prevent false information could be to have page administrators consult dermatologists or have dermatology departments create Facebook pages to educate patients.

In addition to providing health information, Facebook is a source of support for patients. Online communities have been shown to provide patients with a safe space to discuss sensitive topics [14]. In our study, we found that 52\% (26/50) of melanoma Facebook groups were formed primarily for support. Groups not only contribute to social support, but informational, emotional, and esteem support [3]. Melanoma patients can suffer from anxiety, social withdrawal, and denial [15] and online support groups could be therapeutic. Of the groups analyzed, $64 \%$ (32/50) were closed (private), allowing users to have a private space to communicate about their health. In addition to emotional support, Facebook groups are also used for awareness, fundraising, and personal blogs. Facebook groups are therefore $\mathrm{s}$ another avenue for unregulated health care information to be provided over the internet. The inclusion of dermatologists in Facebook groups may be beneficial to ensure there is no misleading or incorrect information provided within the group. One limitation of our study is the small sample size of groups and pages, selection bias, and lack of information regarding the nature of posts in each page.

Future studies should examine more closely how patients are able to interact in these platforms and their experience with Facebook groups and pages. 


\section{Conflicts of Interest}

None declared.

\section{References}

1. Cohen RA, Adams PF. Use of the internet for health information: United States, 2009. NCHS Data Brief 2011 Jul(66):1-8 [FREE Full text] [Medline: 22142942]

2. Cline RJ, Haynes KM. Consumer health information seeking on the Internet: the state of the art. Health Educ Res 2001 Dec;16(6):671-692 [FREE Full text] [Medline: 11780707]

3. Greene JA, Choudhry NK, Kilabuk E, Shrank WH. Online social networking by patients with diabetes: a qualitative evaluation of communication with Facebook. J Gen Intern Med 2011 Mar;26(3):287-292 [FREE Full text] [doi: 10.1007/s11606-010-1526-3] [Medline: 20945113]

4. Diaz JA, Griffith RA, Ng JJ, Reinert SE, Friedmann PD, Moulton AW. Patients' use of the Internet for medical information. J Gen Intern Med 2002 Mar;17(3):180-185 [FREE Full text] [Medline: 11929503]

5. Chou WS, Hunt YM, Beckjord EB, Moser RP, Hesse BW. Social media use in the United States: implications for health communication. J Med Internet Res 2009;11(4):e48 [FREE Full text] [doi: 10.2196/jmir.1249] [Medline: 19945947]

6. Moorhead SA, Hazlett DE, Harrison L, Carroll JK, Irwin A, Hoving C. A new dimension of health care: systematic review of the uses, benefits, and limitations of social media for health communication. J Med Internet Res 2013;15(4):e85 [FREE Full text] [doi: 10.2196/jmir.1933] [Medline: 23615206]

7. Amir M, Sampson BP, Endly D, Tamai JM, Henley J, Brewer AC, et al. Social networking sites: emerging and essential tools for communication in dermatology. JAMA Dermatol 2014 Jan;150(1):56-60. [doi: 10.1001/jamadermatol.2013.6340] [Medline: 24196212]

8. Elkarim GA, Alotaibi NM, Samuel N, Wang S, Ibrahim GM, Fallah A, et al. Social media networking in pediatric hydrocephalus: a point-prevalence analysis of utilization. J Neurosurg Pediatr 2017 May 26:1-6. [doi:

10.3171/2017.3.PEDS16552] [Medline: 28548615]

9. Abedin T, Al MM, Lasker MAA, Ahmed SW, Shommu N, Rumana N, et al. Social Media as a Platform for Information About Diabetes Foot Care: A Study of Facebook Groups. Can J Diabetes 2017 Feb;41(1):97-101. [doi: 10.1016/j.jcjd.2016.08.217] [Medline: 28126155]

10. Facebook. 2017. Pages URL: https://www.facebook.com/help/282489752085908/?helpref=hc fnav[WebCite Cache ID 6zCT1EHK4]

11. Karimkhani C, Green AC, Nijsten T, Weinstock MA, Dellavalle RP, Naghavi M, et al. The global burden of melanoma: results from the Global Burden of Disease Study 2015. Br J Dermatol 2017 Mar 30. [doi: 10.1111/bjd.15510] [Medline: 28369739]

12. Leiter U, Garbe C. Epidemiology of melanoma and nonmelanoma skin cancer--the role of sunlight. Adv Exp Med Biol 2008;624:89-103. [doi: 10.1007/978-0-387-77574-6 8] [Medline: 18348450]

13. Guy GP, Thomas CC, Thompson T, Watson M, Massetti GM, Richardson LC, Centers for Disease ControlPrevention (CDC). Vital signs: melanoma incidence and mortality trends and projections - United States, 1982-2030. MMWR Morb Mortal Wkly Rep 2015 Jun 05;64(21):591-596 [FREE Full text] [Medline: 26042651]

14. Bender JL, Jimenez-Marroquin M, Jadad AR. Seeking support on facebook: a content analysis of breast cancer groups. J Med Internet Res 2011;13(1):e16 [FREE Full text] [doi: 10.2196/jmir.1560] [Medline: 21371990]

15. Söllner W, Gross R, Maislinger S. Psychotherapeutic interventions in melanoma patients. Recent Results Cancer Res 2002;160:362-369. [Medline: 12079235]

Edited by G Eysenbach; submitted 14.07.17; peer-reviewed by R Moza, J Taber; comments to author 23.11.17; revised version received
03.04.18; accepted 03.05.18; published 16.05.18
Please cite as:
Maganty N, Ilyas M, Ginsberg Z, Sharma A
Social Media as a Platform for Information and Support for Melanoma Patients: Analysis of Melanoma Facebook Groups and Pages
JMIR Dermatol 2018;1(1):e2
URL: https://derma.jmir.org/2018/1/e2/
doi: $\underline{10.2196 / \text { derma.8482 }}$
PMID:

CNishita Maganty, Muneeb Ilyas, Zachary Ginsberg, Amit Sharma. Originally published in JMIR Dermatology (http://derma.jmir.org), 16.05.2018. This is an open-access article distributed under the terms of the Creative Commons Attribution License (https://creativecommons.org/licenses/by/4.0/), which permits unrestricted use, distribution, and reproduction in any medium, provided the original work, first published in JMIR Dermatology Research, is properly cited. The complete bibliographic 
information, a link to the original publication on http://derma.jmir.org, as well as this copyright and license information must be included. 